\title{
Investigation into the Physico-Chemical Properties of Soils of Caspian Sea Coastal Area in Mangystau Province
}

\author{
SAMAL SYRLYBEKKYZY ${ }^{1}$, GUSMAN KENZHETAEV ZHARDEMOVICH², \\ NAZIYA SHUKENOVNA SULEIMENOVA ${ }^{1}$, VLADIMIR NIKOLAEVICH PERMYAKOV ${ }^{3}$ \\ and FARIDA KUANTKANOVNANURBAYEVA²
}

${ }^{1}$ Kazakh National Agrarian University Kazakhstan, 050010, Almaty, Abai Street, 8 ${ }^{2}$ Sh. Yesenov Caspian State University, Kazakhstan, 130003, Aktau, Neighbourhood 31

${ }^{3}$ Tyumen State Oil and Gas University Russia, Tyumen, ul. Volodarskogo 56

http://dx.doi.org/10.13005/ojc/300422

(Received: October 25, 2014; Accepted: November 29, 2014)

\begin{abstract}
The article discusses the results of investigation into physico-chemical properties of coastal soils in the areas of oil fields. it has been established that the considered soils are characterized with low content of organics, alkaline reaction of soil solutions, high salinity and weak resistance against anthropogenic impacts. The obtained data can be applied for further studies and monitoring of environment in oil field areas.
\end{abstract}

Keywords. Caspian Sea, positive/negative surge, peninsula, coastal area, oil field, soils, degradation, monitoring, humus, carbonates, salinization, exchange capacity, total salts.

\section{INTRODUCTION}

The article reviews North-Eastern coast, a part of Caspian Lowland in Mangystau Province, which is the most sensitive to sea level fluctuations due to shallow waters. The underwater topography of Caspian Sea towards Bozashy Peninsula is sloping, though a sharp drop to the center of this line can be observed, which stipulates susceptibility of this sea area to the risk of flooding within positive-negative surges. This area can be considered as submerged part of Caspian Lowland.

The major part of the monitored territory is located within the boundaries of New Caspian accretion plain ${ }^{1}$.

In coastal part plain relief patterns dominate, while with increase in distance to sea they are replaced with ridge-hilly-wavy relief. Within 
the boundaries of deposits natural relief forms are violated with various technogenic formations ${ }^{2}$.

The regional peculiarities of soil cover within the considered area are the youth of soils, high rate of complexity, wide development of intrazonal soils, nearly generalized high salinization and carbonateness of soils.

Peculiar feature of soil-forming materials are their high salinization. Salts from deposits are continuously supplied to soil body. However, due to significant influence of sea on soil generation, youth of the territory, nearby surface deposits of mineralized groundwater the most widely spread are intra-zonal soils, meadow coastal soils and solonchaks, and technogenic disturbed soils in areas of deposits ${ }^{3}$.

The processes of soil generation in coastal zone are closely related with fluctuations of modern sea level. The level fluctuations result in flooding and underflooding or drying of already formed soils and landscapes. Within decrease in water level young primitive soils start to form on cleared sea bottom, the processes of desertification of existing landscapes of sea plain can be observed. Sea level rise resulted in formation of hydromorphic conditions of soil generation. Variations of hydrologic conditions related with fluctuations in Caspian Sea level are so dynamic that the signs of soil generation cannot be accumulated and fixed in final products of soil generation ${ }^{4}$.

Steady fixation of signs of occurring soil generation in the soil profile and the process of soil generation require for significantly more extended time period, that is, the soils have no time to complete the overall cycle of soil generation and their profile is characterized both by the signs of previous stages of their development and by properties determined by current conditions of generation.

In accordance with "Natural and agricultural regionalization of land resources of Republic of Kazakhstan" the considered territory belongs to Aral-Caspian Province of desert zone, where the zonal type of soils is brown desert soil ${ }^{1}$.

In terms of agricultural usage the soils are of low value and can serve only as seasonal pastures. Depending on the pattern of anthropogenic impacts the soil degradation is manifested by complete or partial elimination of soil profile, by variation of physical (density, structure, porosity) and chemical (content of humus, ash elements, high molecular compounds, reaction of soil suspension, salinization) properties of soils; violation of water regime; soil pollution with heavy metals, petroleum hydrocarbons and other ingredients. Type and rate of degradation of soil cover depend not only on the impact pattern and its intensively but also on the set of morphological and physico-chemical properties, which determine buffer stability of soils.

In general, the higher is the level of natural soil fertility, the more resistant are they against anthropogenic impact.

Mangystau Province is one of the districts of hydrocarbon production, where large sea and on-land oilfields are concentrated. Coastal zones of the Province experience high environmental burden. Anthropogenic impact is applied to all environmental components: atmospheric air, water, bottom sediments, biota and especially soils of Caspian coastal zone. In this regard the investigations into the state of Caspian coastal soils is a top-priority task aimed at solution of the problem of state estimation of coastal soils ${ }^{5}$.

\section{EXPERIMENTAL}

The main source of actual information consists of the materials of our proprietary studies performed at stationary ecological stations in coastal zone of Caspian Sea ${ }^{6}$.

Procedure of soil sampling and methods of laboratory experiments meets the requirements of conventional practices, which makes it possible to preserve consistence of observations and facilitates comparison of the data with subsequent studies.

\section{RESULTS AND DISCUSSION}

In order to study physico-chemical properties of soils the specimens were exposed to 
laboratory determination of humus content, total nitrogen, bulk phosphorus, composition of absorbed bases, reaction of water suspensions, content of calcium carbonates, water soluble salts ${ }^{7}$.

\section{Karazhanbas Oil Field}

Stationary ecological posts SEP-1, SEP-

2, SEP-3 and SEP-4 at Karazhanbas Oil Field are located on meadow coastal soils, coastal solonchaks and on technogenic disturbed grounds [8]. Within soil monitoring in 2013 the sampling for chemical analysis for investigation into physicochemical properties of soils was performed by genetic horizons, and in 2014 by the strata $0-5$ and $5-20 \mathrm{~cm}$. Therefore, the data of chemical analysis for physico-chemical properties are not compared in this section. The soils of the deposit are depleted with humus due to their youth. Humus content in the upper horizons of the deposit soils varies in wide ranges from 0.07 to $1.04 \%$.

Downstream the profile the humus content is also not higher than $1 \%$ and varies in the ranges of $0.09-0.40 \%$. The content of nitrogen in the humus horizon varies in the ranges of $0.03-0.15 \%$. The content of bulk phosphorus is also not characterized with any definite regularities. In the upper horizons the concentration of bulk phosphorus varies in the ranges of $400-1087.5 \mathrm{mg} / \mathrm{kg}$ (Fig. 1).

Downstream the profile the content of bulk phosphorus is not characterized with any definite regularities. Relatively high amplitude of variations in content of fertilizer elements is not related with soil processes but stipulated with the existence of organic substance on surface and in the profile transferred from above areas.

The reaction of water suspensions in the soils is either weakly alkaline, or close to neutral (pH 6.85-7.40). The soils are characterized with very high content of carbonates, both from the surface and in the profile. Their amount varies from 1.39 to $9.19 \%$. The exchange capacity varies in wide ranges from 6.15 to $22.63 \mathrm{mg}$-eq/100 g of soil (Fig. 1)

As a rule, the heavier is the soil grading, the higher is the exchange capacity. Exchangeable magnesium dominates among absorbed bases. In fact, all soils at the oil field are salinized. As can be seen in the results of determination of water extract composition, the content of total salts varies from 0.08 to $6.29 \%$. (Fig. 1$)^{9}$.

Herewith, minimum amount of salts is characteristic for upper horizons of soils at the stage of desertification, where the salts from the surface horizons are washed out to certain depth (SEP-3).

Water-salt regime of soils in marine plain is unstable. Its resultant manifestation depends even on insignificant variations in surface microrelief and on properties of ground, which determine water-raising capacity, on mineralization and on groundwater depth, on weather conditions and on other numerous factors. In addition, the character of salinization of marine deposits is also highly important ${ }^{10}$.

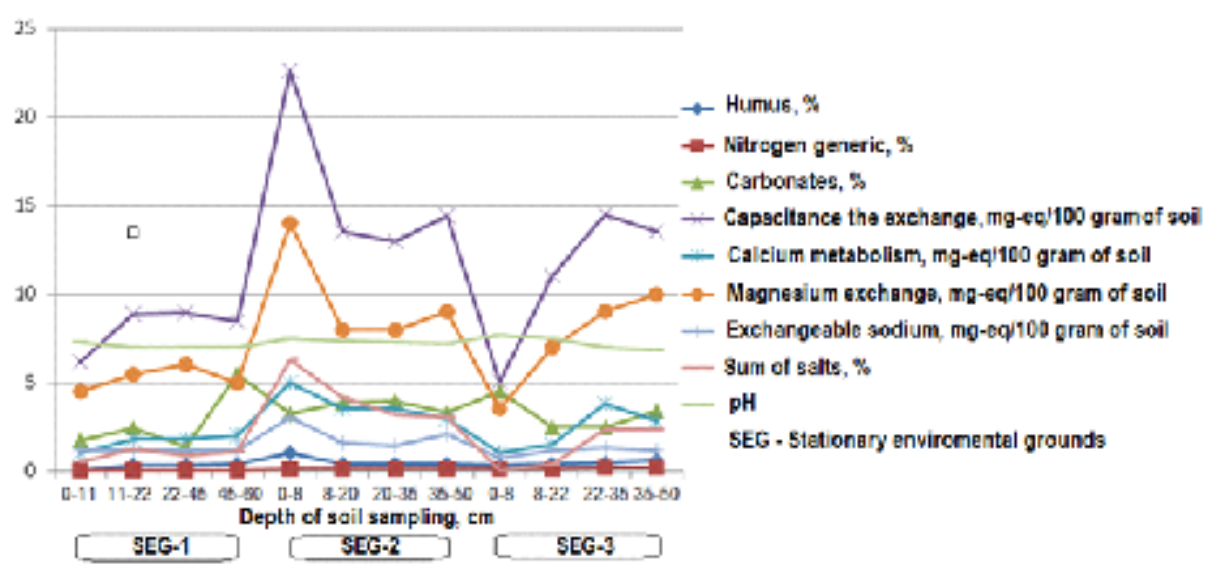

Fig. 1: Physico-chemical properties of coastal soils 
In terms of chemistry of salinization the most common are chloride-sulfate type - by anions and calcium-sodium type - by cations. The soils with sulfate-chloride, chloride and sodium types of salinization chemistry also can be met.

\section{Arman Oil Field}

The structure of soil cover of Arman Oil Field consists mainly of combinations of marine meadow soils with marine solonchaks. In surging area (SEP-8) marsh solonchaks have been outlined. The soils within the oil field territory, and of overall coastal strip, are characterized with low content of humus, $0.21-0.56 \%$. In the upper horizon of soils at SEP-7, located westwards from the oil field, the content of humus is $1.07 \%$.
The content of bulk phosphorus and total nitrogen in upper horizons is also low and varies in the ranges of $458-744 \mathrm{mg} / \mathrm{kg}$ and $0.03-0.05 \%$, respectively (Fig. 2). Depending on the content of organic and mineral colloids, the exchange capacity varies in wide ranges of $8.3-18.7 \mathrm{mg}$-eq/100 $\mathrm{g}$. Magnesium cation dominates in the composition of absorbed bases (Fig. 2). The content of carbonates is $1.6-4.3 \%$. The reaction of water suspension is neutral or weakly alkaline, $\mathrm{pH}$ 6.97-7.28. The soils of the oil field are characterized with very high rate of salinization, however, in the boundaries of SEP9 the soils are salinized to low or moderate extent. The type of salinization chemistry is chloride-sulfate, sodium.

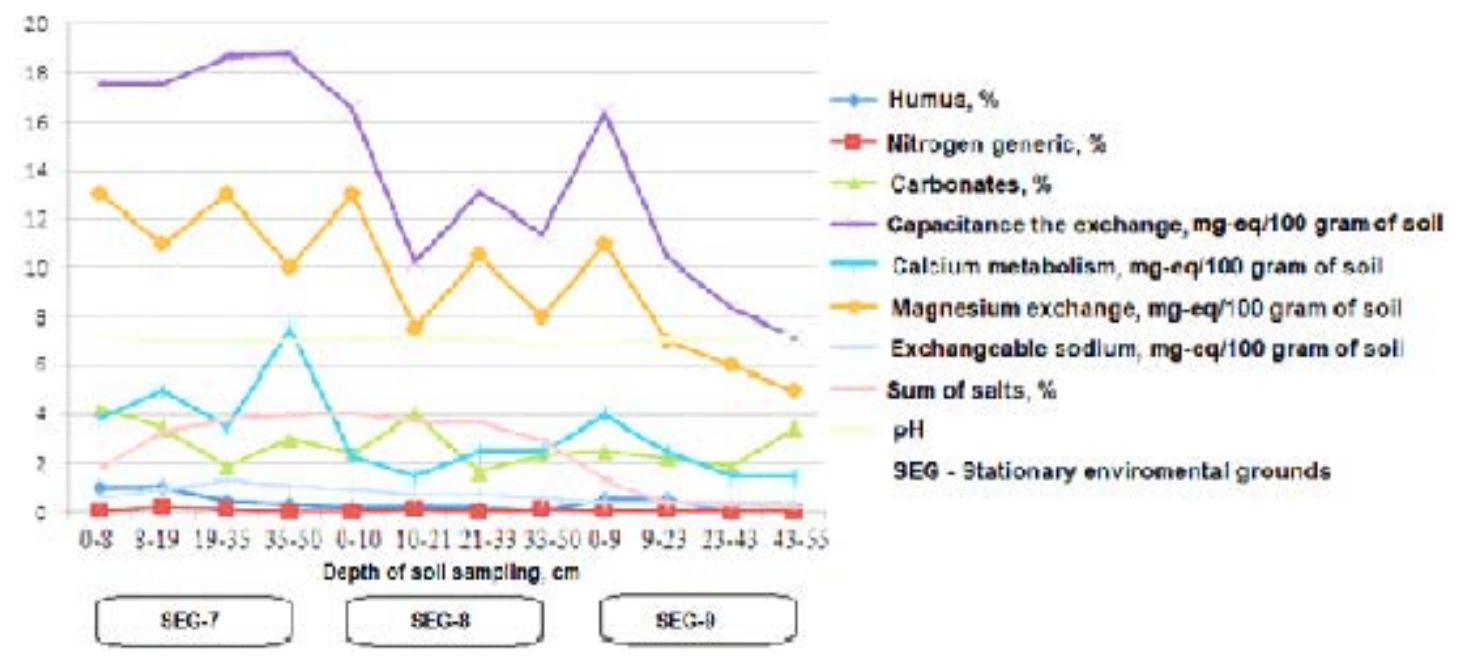

Fig. 2: Physico-chemical properties of coastal soils

\section{Kalamkas Oil Field}

Sor-affected solonchaks and technogenic disturbed grounds dominate in the composition of soil cover at Kalamkas Oil Field. All soils of the oil field are characterized with low reserves of organics. The content of humus in the upper stratum is 0.29 $0.49 \%$. Downstream the profile the content of humus usually decreases, but in some cases (SEP-12) in the stratum $32-55 \mathrm{~cm}$ it can increase to $1 \%$. (Fig. 3). The content of total nitrogen in the upper horizons varies in the ranges of 0.07-0.16\%. The amount of bulk phosphorus varies in wide range of 458-859 $\mathrm{mg} / \mathrm{kg}$. Reaction of water suspensions in the soils2 of the oil field is mainly neutral $(\mathrm{pH} \mathrm{6.9-7.3).} \mathrm{The}$ exchange capacity depends on numerous factors: mechanical composition, humus content, salinization; therefore, its value varies in wide ranges from 11.0 to $22.03 \mathrm{mg}-\mathrm{eq} / 100 \mathrm{~g}$ of soil. Exchangeable magnesium dominates in the composition of absorbed bases (65-85\% of exchange capacity), the next position is occupied by calcium cation (10-35 \% of exchange capacity) (Fig. 3).

The soil cover of the oil field is everywhere exposed to intensive salinization, the qualitative and quantitative indices of which vary in wide ranges. The content of salts varies in the range of $3.2-8.5 \%$, 
which corresponds to a very high extent of salinization (Fig. 3). The chemistry is as follows: the most common are sulfate-chloride and chloride- sulfate types - by anions, and calcium, sodium, calcium-sodium types - by cations.

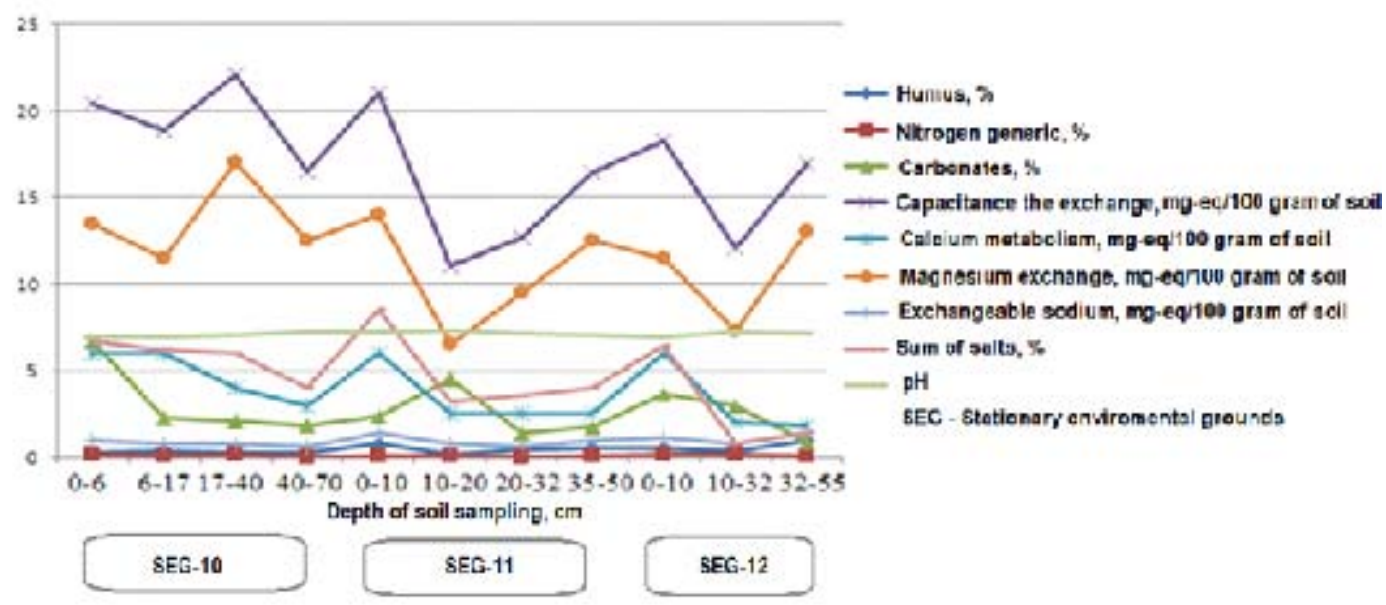

Fig. 3: Physico-chemical properties of coastal soils

\section{Background}

Background monitoring sites were located on solonchaks of marine (SEP-6) and meadow marine soils (SEP-5). The content of humus in surface horizons of meadow marine soils is 0.95 $\%$, in marine solonchaks $0.85 \%$.

Downstream the profile the content of humus sharply decreases. The soils in background sites are weakly supplied with biogenic elements, total nitrogen and bulk phosphorus.
Their content in surface horizons amounts to $0.08-0.13 \%$ and $1087-1145 \mathrm{mg} / \mathrm{kg}$, respectively. Reaction of water suspension is close to neutral or weakly alkaline type. As all marine soils, the soils of background sites are characterized with increased carbonate content (Fig. 4).

The exchange capacity in the soils of background site varies in wide ranges from 7.5 to $16 \mathrm{mg}$-eq per $100 \mathrm{~g}$ of soil. Magnesium cations dominate in the composition of absorbed bases.

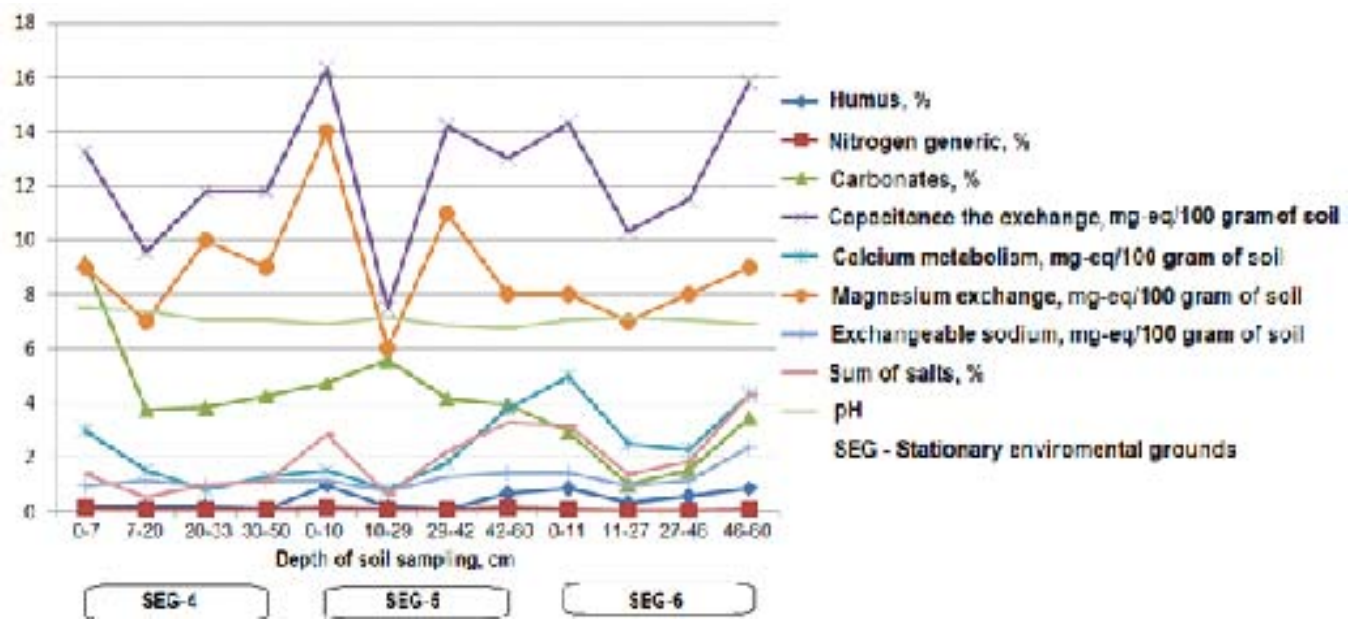

Fig. 4: Physico-chemical properties of coastal soils 
Solonetzicity of the soils is not morphologically expressed, though rather frequently the portion of exchangeable sodium amounts to $10 \%$ of the exchange capacity. The soils in background sites are exposed to strong salinization. The total content of salts in the soil profile varies from 0.64 to $4.33 \%$ (Fig. 4).

The salinization chemistry is of chloridesulfate type - by anions, and of calcium-sodium type - by cations.

On the basis of the study into physicochemical properties of soils it is possible to conclude that the considered soils are characterized with low content of organic matters, alkaline reaction of soil solutions, high salinization and weak resistance against anthropogenic impacts. At present the soil cover is exposed to strong disturbances directly in the boundaries of oil fields and adjacent sites. The soil disturbances in other sites are not related with oil production. The pattern of soil profile in sampling locations is illustrated in Fig. 5.

The schematic map of location of soil monitoring posts in Caspian coastal zone in the vicinity of oil fields, made in Google and including space images, is illustrated in Fig 6.

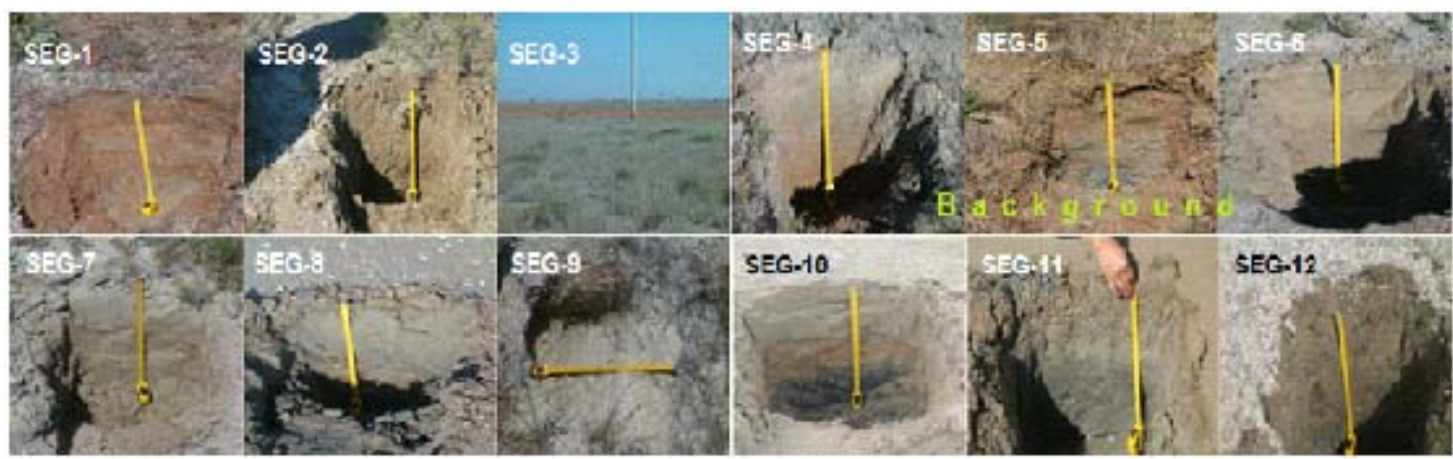

Fig. 5: Pattern of soil profile in sampling locations

\section{Final Remarks}

The character of soil cover, soil properties, biochemical and chemical processes occurring in the soils influence on purity and composition of atmosphere, surface and underground waters, environmental situation for life space. Soil records and stores in its genetic profile the highest amount of information about long-term periods of development of geographic medium. It has been established that salinization of soils leads to physical degradation of grounds (impairment of physical properties hindering or preventing execution of soil functions). In its turn, physical degradation of soils initiates numerous natural disasters. Herewith, an important role is played by peculiar features of territory. Overall increase in surface areas of salinized soils and subsequent reduction of croplands lead to necessity of environmental estimation of salinized soils in terms of their ecological state.
The procedures and methods of investigations into physical properties and regimes of salinized soils is poorly developed, since a set of properties in salinized soils cannot be reliably determined by conventional methods of soil sciences and ecology.

The main criterion of estimation of soil physical state is consistency of the set of soil properties with the character of functions performed by soil in certain landscape.

In this regard, first of all, it is necessary to establish, how and to what extent the amount of salts influences on ecological functions performed by soil due to modification of physico-chemical properties.

Based on the results of investigations into physico-chemical properties of soils it is possible to arrive at the conclusion that the considered soils 


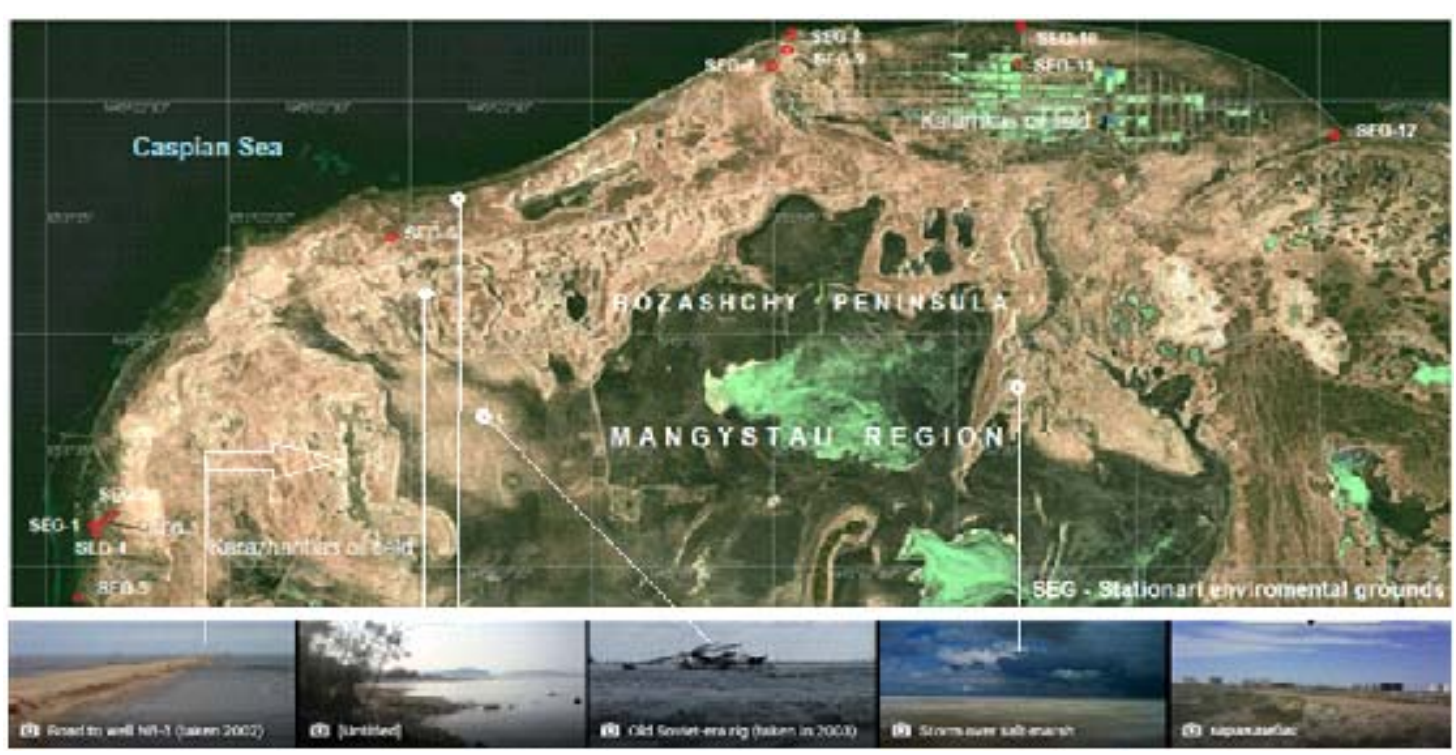

Fig. 6: Schematic map of location of monitoring posts (SEP) (made in Google)

are characterized with low content of organic matter, alkaline reaction of soil solutions, high salinization and weak resistance against anthropogenic impacts.

\section{CONCLUSIONS}

As a consequence of the investigations it has been established that the physico-chemical properties of the soils are relatively steady. Thus, their study can be performed once per three years.

\section{ACKNOWLEDGMENTS}

The work was supported by the grant of Ministry of Education and Science of Republic of Kazakhstan, \# 011202173 devoted to the project "Scientific background of complex investigation into the components of environment of Caspian coastal area and technogenic entities".

\section{REFERENCES}

1. Faizov K. Sh. Soils of desert zone of Kazakhstan. Alma-Ata, 1970.

2. Faizov K. Sh., Urazaliev R. A., and lorganskiy A. I. Soils of Republic of Kazakhstan. Almaty, 2001, 194-215.

3. Borovskiy V. M. Geochemistry of salinized soils of Kazakhstan. M., 1978.

4. http://www.kazhydromet.kz/ru/obzor vody// Forecast of levels of Caspian Sea in its unfrozen part for January 23-28, 2014.

5. Samal Syrlybekkyzy., Gusman Z. Kenzhetayev., Aliya R. Togasheva. Lyaylim S. Tayzhanova. 17-Year Periods of Rising and Falling Water Levels in the Kazakhstan Section of the Caspian Sea // European
Researcher, 2014, 69, \# 2-2, p. 401-412.

6. State ecological monitoring in shelf and coastal area of Caspian Sea using aerospace distant sounding. 2010. Final Report.

7. Russian Federation Standard GOST 17.4.4.02-84. Environmental protection. Soil. Methods for sampling and preparation of soil for chemical, bacteriological and helminthological analysis.

8. Kenzhetaev G. Zh., Syrlybekkyzy S., Dzhumasheva K. A., and Koibakova S. E. Analysis of impact of oil fields on pollution of soil in Caspian coastal zone // Innovative Development of Oil and Gas Complex, 
International Scientific and Practical Conference, Proceeding, Part 2, Aktau, 2013, pp. 412-416. Caspian Sea: Hydrology and Hydrochemistry. M.: Nauka, 1986. 262 p.

9. Amador Jose A. Finescale spatial variability of physical and biological soil properties in Kingston, Rhode Island / Amador Jose A.,
Wang Yong, Savin Mary C., Gorres Josef H. / / Geoderma. 2000, 98(1-2), C. 8394.

10. Miralles I. Degradación del suelo por exceso de sales y su relación con la topografía en un area del sur de Espania / Miralles I., Ortega R., Canton Y., Asensio C. // Agrochimica. 2002, 46(6), C 270-279. 